\title{
Sealing performance of a universal adhesive in the root canal: evaluation at six and twelve months
}

\author{
Geneviève Grégoire ${ }^{1 *}$, Yasin Ahmed ${ }^{2}$, Aurélien Favaretto ${ }^{3}$, Marie-Paule Lacomblet ${ }^{4}$ and Florent Destruhaut $^{5}$ \\ ${ }^{1}$ Professor, Faculty of Odontology, University Toulouse III, and University Paris Descartes, France \\ ${ }^{2}$ Faculty of Odontology, University Toulouse III, France \\ ${ }^{3}$ Faculty of Odontology, University Toulouse III, France \\ ${ }^{4}$ Research and Training Technician, Faculty of Odontology, University Toulouse III, France \\ ${ }^{5}$ Assistant Professor, Faculty of Odontology, University Toulouse III, France
}

\begin{abstract}
The primary purpose of a post is to retain the coronal restoration in an endodontically treated tooth that has suffered an extensive loss of crown structure. The success of posts depends of the quality of the bonding between the post, resin cement and root dentin. The adhesive system is a key factor in ensuring immediate and durable sealing and long-term retention. Our study is designed to evaluate the sealing of a canal with fiber post anchor after using universal adhesive system Prime\&Bond active with the two strategies, total-etch-and-rinse or self-etch comparing with an etch-and-rinse adhesive, Prime\&Bond XP. The non-destructive measurement of fluid flow through endodontically treated teeth with fiber posts was followed repeatedly during a one year aging period.
\end{abstract}

The results show that the universal adhesive gives the same results regardless of its strategy of use and these results remain stable at 6 and 12 months.

\section{Introduction}

The primary purpose of a post is to retain the coronal restoration in an endodontically treated tooth that has suffered an extensive loss of crown structure. The bonding of a fiber post presents multiple clinical interests for the restoration of the endodontically treated tooth [1]. The removal of any metal structure avoids the phenomena of corrosion and brings many advantages in terms of biocompatibility and aesthetics. The bonding of these posts leads to a better mechanical resistance thanks to the distribution of the stresses at the level of the root walls, especially since the modulus of elasticity of the adhesive system is similar to that of the tooth $[2,3]$. The success of posts depends of the quality of the bonding between the post, resin cement and root dentin. The adhesive system is a key factor in ensuring immediate and durable sealing and long-term retention. In clinical practice there is a choice to be made between three types of products and procedures: the older traditional adhesives applied following a standard total-etchand-rinse step or the more contemporary self-etch products which avoid the phosphoric acid etching. The third class of adhesives allows using both procedures (either one) as they can be used either like the self-etch adhesives or following an etching step and are therefore termed universal. There is an advantage in having an adhesive that can operate on these two procedures since it allows the dentist to choose his procedure according to the clinical case in order to optimize the final result. When the adhesive system is used at the root level in bonding a post, we note lower adhesion values at the post's third apical, the access and the technique being more difficult than for the third coronary $[4,5]$.

The in vitro dentin permeability was evaluated by measuring the hydraulic conductance through the treated root canal. This measurement can be used to compare different adhesive systems $[6,7]$.
This non-destructive technique makes it possible to carry out several measurements on the same sample of roots of different periods, which makes it possible to observe possible variations in the time [8]. In this study we evaluated a universal adhesive used according to its two strategies.

The working hypothesis is that despite the two different substrates, the end products should behave in similar manner and yield identical functional results which remain stable without any permeability difference over time.

\section{Methods and materials}

Eighteen single-rooted non-carious teeth, extracted for periodontal reasons, free of cracks and fractures and with fully developed apices were used in this study.

The coronal portions were removed to achieve uniform lengths of $15 \mathrm{~mm}$ using a low-speed saw (Isomet 2000; Buehler, Evanston, Ill.) equipped with a rotating diamond-impregnated copper disk (11-4244; Buehler) under constant water irrigation. The teeth were stored in $10 \%$ chloramine solution at $4^{\circ} \mathrm{C}$ until use.

*Correspondence to: Geneviève Grégoire, Faculté de Chirurgie Dentaire, 3 chemin des Maraîchers, TOULOUSE, France, Tel: +33 (0)5 621729 29; E-mail: genevieve.gregoire@univ-tlse3.fr

Key words: fluid filtration, universal adhesive, bonding technique, fiber post, aging

Received: July 10, 2019; Accepted: September 09, 2019; Published: September 12,2019 


\section{Specimens preparation}

The pulp tissue was removed with a barbed broach. The working length was established by substracting $1 \mathrm{~mm}$ from the observed length when the tip of a \#10 file appears at the apex.

Boring was realized with ProTaper Next Ni-Ti rotary files (DentsplyMaillefer) to iso-size 40, 0.06 taper (400 rpm at maximum), on the whole working length until the enlargement was achieved. Each canal was copiously irrigated with $3 \%$ sodium hypochlorite between each instrument use. Following the boring, the canal was irrigated with $3 \mathrm{~mL}$ of $14 \%$ aqueous EDTA, blotted dry with paper cone-tips and obturated with gutta-percha cones and $\mathrm{AH}$ Plus cement according to the cold lateral condensation technique: a cement coated master-cone and a finger-spreader were inserted in the canal at one $\mathrm{mm}$ from the limit of working length; lateral compaction was realized with guttapercha cones to seal off the canal. Lateral condensation of cold guttapercha is considered as the most effective and simple technique $[9,10]$.

After canal obturation, all the roots were evaluated regarding the quality of obturation by taking radiography and the external surface of the roots were covered with two layers of varnish to prevent leakage.

\section{First measurement of hydraulic conductance after root canal obturation}

The cervical part of the obturated tooth was centered on a polycarbonate disc made in the authors' laboratory with a 1.2 $\mathrm{mm}$ diameter circular perforation in its center and secured with cyanoacrylate glue so as to put it at the entrance of the root canal.

The hydraulic penetration $\left(200 \mathrm{~cm} \mathrm{H}_{2} \mathrm{O}\right)$ through the obturated tooth was evaluated by measuring the passage of physiologic saline. The liquid from the perfusion bag (Baxter B1322 bag; Viaflex) left the chamber through high-pressure connectors, made using polyethylene tubing (Dupont de Nemours, Wilmington, Del.) having a stable internal diameter of $0.2 \mathrm{~mm}$. The measuring system proper, Flodec (De Marco Engineering, Geneva, Switzerland), was composed of a glass capillary tube $370 \mathrm{~mm}$ long and $0.75 \mathrm{~mm}$ in internal diameter, and an optical sensor on a mounting that could travel along the tube, automatically following the movement of the bubble and expressing it as an electrical signal. The movement of the mounting was controlled electronically by the Flodec system. The resolution threshold for the system was $0.005 \mathrm{~mm}$, corresponding to a liquid flow of 2.208 nanoliters. The input of the capillary tube was connected to the pressurized chamber and the output to a specimen holder. The electric signal obtained from the Flodec system was processed by a computer (Prolinea 4/33; Compacq, Issy-les-Moulineaux, France) to show linear displacement of the bubble and flow variation over time and surface area. The linear displacement of the bubble was converted into hydraulic conductance by the formula: $\mathrm{Lp}=\mathrm{Jv} /$ (A $\cdot \Delta \mathrm{P} \cdot \mathrm{t}$ ) [where $L p$ is hydraulic conductance in $\mu \mathrm{l} . \mathrm{cm}^{-2} \cdot \mathrm{min}^{-1} . \mathrm{cm} \mathrm{H}_{2} \mathrm{O}^{-1}, J v$ is fluid flow in $\mu \mathrm{l}, A$ is sample surface area in $\mathrm{cm}^{2}, \Delta P$ is hydraulic pressure gradient in $\mathrm{cm} \mathrm{H}_{2} \mathrm{O}$ and $t$ is time in minutes].

Fluid movement, or $\mathrm{Jv}$, was calculated from $\mathrm{mm}$ of bubble movement per minute. Measurements were made at 30 -second intervals for 15 minutes and the mean of the values obtained was calculated for each specimen of each series. The results were expressed as graphs or tables.

The polycarbonate specimen holder (made in the authors' laboratory) (Figure 1) was designed. There were 2 parts to the holder: an upper part connected to the measuring system and having a bleed valve to eliminate air bubbles (which would otherwise influence the conductance values), and a specimen support area. The 2 parts were bolted together and the joint was sealed by high pressure O-rings. The system was checked for leaks by inserting an impermeable specimen holder. The test specimen was placed in the holder so that the pressure was applied to the root canal.

The mean value is called "reference obturation" (M1). The coronal portion of filled roots was temporarily sealed with IRM (Dentsply Caulk, Milford, USA) based on the type of adhesive they would receive.

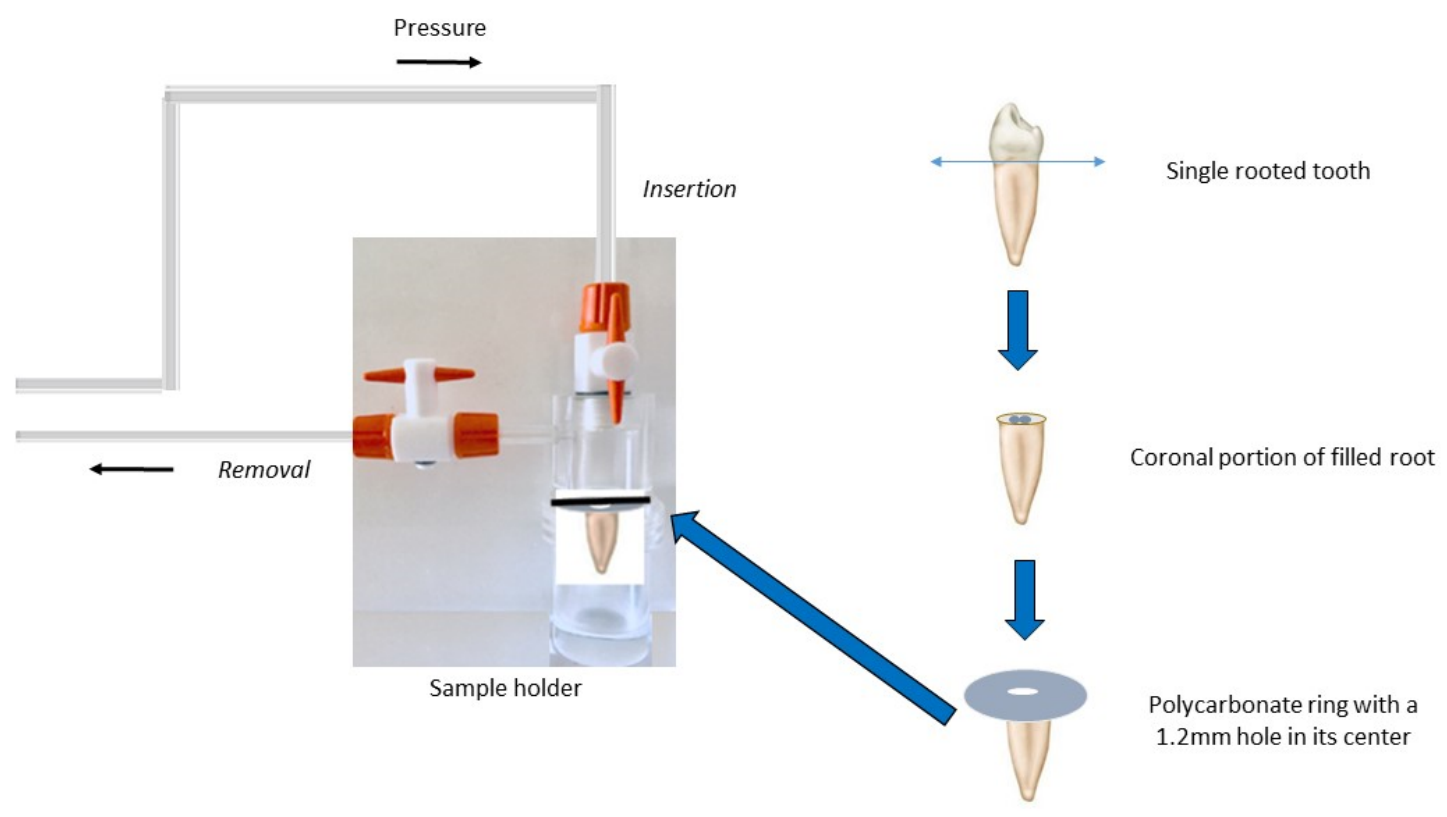

Figure 1. Sample holder: experimental set-up 


\section{Randomization}

Specimens were then randomly divided into 3 groups of 6 by drawing lots. Each group A, B and C were used for fixing a fiber post (X-Post Endodontic Fiber Post, Dentsply) according to a different protocol:

- Group A: 6 teeth were used for fixing the posts with Prime\&Bond active/ Self Cure Activator; Etch-and-Rinse and Core.X Flow

- Group B: 6 teeth were used for fixing the posts with Prime\&Bond active/ Self Cure Activator; Self Etch and Core.X Flow

- Group C: 6 references were taken for fixing the posts with Prime\&Bond XP/Self Cure Activator; Etch-and-Rinse; and Core.X Flow (Control Group)

\section{Preparation of the canal empty space and fixing the obturator}

After removing the temporary coronal seal, a $7 \mathrm{~mm}$ deep post space was drilled in each root using a universal DT drill of black color with a speed of $1500 \mathrm{rpm}$. The space was shaped with a DT Finishing Drill corresponding to a Dentsply post at a speed of $1500 \mathrm{rpm}$.

For each group, the corresponding adhesive was applied on the whole surface of the canal and on the post, depending on the manufacturer's protocol (Tables 1 and 2). After removing the adhesive solvent by gently drying, the Core-X Flow was applied into the post space using root canal applicator tips and the post seated. A polymerization flash was done (SmartLite, Dentsply, at $1200 \mathrm{~mW} / \mathrm{cm}^{2}$ intensity).

\section{Measurement of hydraulic conductance through dentin adhesives in endodontically treated teeth}

For each sample, the post was sectioned so as the cervical part of the root can be glued on the perforated disk and the sample is left at room

Table 1. Composition of the used products

\begin{tabular}{|c|c|c|}
\hline Products & Composition & $\begin{array}{l}\text { Batch } \\
\text { number }\end{array}$ \\
\hline $\begin{array}{l}\text { Prime\&Bond active } \\
\text { DENTSPLY DE TREY } \\
\text { GmbH, Konstanz, } \\
\text { Germany }\end{array}$ & $\begin{array}{l}\text { Phosphoric acid modified acrylate resin; } \\
\text { Multifunctional acrylate; } \\
\text { Bifunctional acrylate; } \\
\text { Acidic acrylate; } \\
\text { Isopropanol; } \\
\text { Water; Initiator; Stabilizer }\end{array}$ & 17100544 \\
\hline $\begin{array}{l}\text { Prime\&Bond XP } \\
\text { DENTSPLY DE TREY } \\
\text { GmbH, Konstanz, } \\
\text { Germany }\end{array}$ & $\begin{array}{l}\text { Carboxylic acid modified dimethacrylate (TCB } \\
\text { resin); } \\
\text { Phosphoric acid modified acrylate resin } \\
\text { (PENTA); } \\
\text { Urethane dimethacrylate (UDMA); } \\
\text { Triethyleneglycol dimethacrylate (TEGDMA); } \\
\text { 2-Hydroxyethylmethacrylate (HEMA); } \\
\text { Butylated benzenediol (stabilizer); } \\
\text { Ethyl-4(dimethylamino)benzoate; } \\
\text { Camphorquinone; Functionalised amorphous } \\
\text { silica; } \\
\text { Tertiary butanol }\end{array}$ & 1710000592 \\
\hline $\begin{array}{l}\text { Self Cure Activator } \\
\text { DENTSPLY DE TREY } \\
\text { GmbH, Konstanz, } \\
\text { Germany }\end{array}$ & $\begin{array}{l}\text { Mono- and di-methacrylate resins; } \\
\text { Catalyst; Photoinitiators; Stabilizers; } \\
\text { Acetone; } \\
\text { Water }\end{array}$ & 170614 \\
\hline $\begin{array}{l}\text { DE TREY Conditioner } 36 \\
\text { DENTSPLY DE TREY } \\
\text { GmbH, Konstanz, } \\
\text { Germany }\end{array}$ & $\begin{array}{l}\text { Phosphoric acid; } \\
\text { Highly dispersed silicon dioxide; } \\
\text { Detergent; Pigment; Water }\end{array}$ & 1710000133 \\
\hline $\begin{array}{l}\text { Core-X Flow } \\
\text { DENTSPLY DE TREY } \\
\text { GmbH, Konstanz, } \\
\text { Germany }\end{array}$ & $\begin{array}{l}\text { Urethane Dimethacrylate; } \\
\text { Di- \& Tri-functional Methacrylates; } \\
\text { Barium Boron Fluoroaluminosilicate Glass; } \\
\text { Camphorquinone (CQ) Photoinitiator; } \\
\text { Photoaccelerators; } \\
\text { Silicon Dioxide; } \\
\text { Benzoyl Peroxide; }\end{array}$ & 1710000850 \\
\hline
\end{tabular}

Table 2. Instructions for use of the adhesive systems tested

\begin{tabular}{|c|c|}
\hline Adhesive systems & Protocols \\
\hline $\begin{array}{l}\text { Group A } \\
\text { Prime\&Bond active } \\
\text { Universal adhesive } \\
\text { used in etch-and-rinse } \\
\text { mode }\end{array}$ & $\begin{array}{l}\text { - Apply phosphoric acid (DeTrey Conditioner } 36 \text { ) according to } \\
\text { manufacturer's instructions for } 15 \mathrm{~s} \text { to intraradicular dentin and } \\
\text { then rinse for } 15 \mathrm{~s} \text { with } 0.9 \% \mathrm{NaCl} \text { solution; } \\
\text { - remove rinsing solution with paper points; } \\
\text { - do not desiccate dentin; } \\
\text { - mix adhesive and Self Cure Activator (ratio } 1 / 1 \text { ) for } 2 \mathrm{~s} \text {; } \\
\text { - proceed immediately to application of adhesive/activator; } \\
\text { - keep adhesive/activator slightly agitated for } 20 \mathrm{~s} \text {; } \\
\text { - disperse adhesive/activator and remove solvent with a } \\
\text { moderate clean, dry air flow for at least } 5 \mathrm{~s} \text {. }\end{array}$ \\
\hline $\begin{array}{l}\text { Group B } \\
\text { Prime\&Bond active } \\
\text { Universal adhesive } \\
\text { used in self-etch mode }\end{array}$ & $\begin{array}{l}\text { - Mix adhesive and Self Cure Activator (ratio } 1 / 1 \text { ) for } 2 \mathrm{~s} \text {; } \\
\text { - proceed immediately to application of adhesive/activator; } \\
\text { - keep adhesive/activator slightly agitated for } 20 \mathrm{~s} \text {; } \\
\text { - disperse adhesive/activator and remove solvent with a } \\
\text { moderate clean, dry air flow for at least } 5 \mathrm{~s} \text {. }\end{array}$ \\
\hline $\begin{array}{l}\text { Group C } \\
\text { Prime\&Bond XP } \\
\text { Etch-and-rinse } \\
\text { adhesive (control) }\end{array}$ & $\begin{array}{l}\text { - Apply phosphoric acid (DeTrey Conditioner } 36 \text { ) according to } \\
\text { manufacturer's instructions for } 15 \mathrm{~s} \text { to intraradicular dentin and } \\
\text { then rinse for } 15 \mathrm{~s} \text { with } 0.9 \% \mathrm{NaCl} \text { solution; } \\
\text { - remove rinsing solution with paper points; } \\
\text { - do not desiccate dentin; } \\
\text { - mix adhesive and Self Cure Activator (ratio } 1 / 1 \text { ) for } 2 \mathrm{~s} \text {; } \\
\text { - proceed immediately to application of adhesive/activator; } \\
\text { - maintain contact of adhesive/activator with tooth structure for } \\
\text { at least } 20 \mathrm{~s} \text {; } \\
\text { - remove solvent with a moderate clean, dry air flow for at least } 5 \mathrm{~s} \text {. }\end{array}$ \\
\hline
\end{tabular}

temperature for 24 hours. The measurements were done as previously indicated and the average of each group was calculated (M2).

\section{Aging}

The samples with the bonded fiber post were kept in a humid atmosphere for 12 months. Hydraulic conductance measurements were done after 6 months (M3) and then 12 months (M4).

\section{Statistical analysis}

The statistical analysis comprised an analysis of the mean and standard deviation for each test group, an analysis of variance, a posteriori test (Duncan's new multiple range). A significant level of 0.05 was used for all tests.

\section{Results}

It is noted that the seal increases after bonding of the posts compared to the initial sealing regardless of the adhesive system used in the study. The Prime \& Bond active self-etch (Group B) provided a better seal than the etch-and-rinse strategy (Group A) at 24 hours but also at 6 months and 12 months. The sealing obtained for Group A was more efficient than for Prime \& Bond XP (Group C) at 24 hours and 6 months but equal to 12 months (with the method used, the lower values are better) (Table 3 ).

The values obtained between the reference root canal filling and the reconstructions with posts using the three different adhesive methods were always statistically different (Table 4 ).

At 24 hours, when the Prime \& Bond adhesive was used according to the etch-and-rinse or self-etch strategy, the difference was not significant $(p=0.187)$, just as there was no difference between the results of the Prime $\&$ Bond active etch-and-rinse and those of the Prime \& Bond XP $(p=0.112)$. On the other hand, the Prime \& Bond active self-etch was significantly different from the Prime \& Bond XP $(\mathrm{p}=0.005)$.

For each system, measurements during aging were not statistically different for both the Prime \& Bond active strategies and the Prime \& Bond XP at 24 hours, 6 months or 12 months ( $>>0.05)$. But if we 
Table 3. Means and standard deviations (SD) of test specimen hydraulic conductance $\left(\mu l . \mathrm{cm}^{2} . \mathrm{min}^{-1} . \mathrm{cm} \mathrm{H}_{2} \mathrm{O}^{-1}\right)$ following root canal obturation and endodontic post cementation at times 24 hrs, 6 months and 12 months

\begin{tabular}{|c|c|c|c|}
\hline \multirow{2}{*}{$\begin{array}{l}\text { Root canal obturations with the use of gutta-percha cones and AH Plus cement } \\
\text { Experimental groups }\end{array}$} & \multicolumn{3}{|c|}{$\begin{array}{l}\text { M1 (Reference Obturation) } \pm \text { SD } \\
902 \pm 112\end{array}$} \\
\hline & $\begin{array}{l}\text { M2 (T } 24 \text { hrs) } \\
\quad \pm \text { SD }\end{array}$ & $\begin{array}{c}\text { M3 (T } 6 \text { months) } \\
\pm \text { SD }\end{array}$ & $\begin{array}{c}\text { M4 (T } 12 \text { months) } \\
\pm \text { SD }\end{array}$ \\
\hline Group A: X-Post/Core-X flow/Prime\&Bond active Etch-and-Rinse and Self Cure Activator & $732 \pm 56$ & $756 \pm 32$ & $786 \pm 27$ \\
\hline Group B: X-Post/ Core-X flow /Prime\&Bond active Self-Etch and Self Cure Activator & $670 \pm 74$ & $687 \pm 61$ & $704 \pm 64$ \\
\hline Group C: X-Post/ Core-X flow / Prime\&Bond XP Etch-and-Rinse and Self Cure Activator & $809 \pm 68$ & $809 \pm 49$ & $783 \pm 62$ \\
\hline
\end{tabular}

Table 4. ANOVA table of variation of fluid filtration of reference fillings compared to all the fillings with posts. Duncan's test indicates two groups ( $\mathrm{p}<0.05$ )

\begin{tabular}{|l|c|c|c|c|}
\hline Source & Degree of freedom & $\begin{array}{l}\text { Sum of } \\
\text { squares }\end{array}$ & F & P value \\
\hline $\begin{array}{l}\text { Root canal preparation } \\
\text { (reference vs posts) }\end{array}$ & 1 & 244172 & 24.563 & 0.000020 \\
\hline Specimens & 34 & 9941 & 0.00137 \\
\hline
\end{tabular}

Table 5. ANOVA table of variation of fluid filtration as repeated measurement at 24 hours and 12 months

\begin{tabular}{|l|c|c|c|}
\hline Source & Degree of freedom & Sum of squares & P value \\
\hline Bonding agent & 2 & 74397 & 15.640 \\
\hline Specimens & 15 & 35677 & \\
\hline Time & 1 & 3919 & 0.000214 \\
\hline Time * bonding agent & 2 & 10243 & 0.804 \\
\hline Time * specimens & 15 & 73104 & 1.051 \\
\hline
\end{tabular}

compared the Prime \& Bond active self-etch to Prime \& Bond XP, the difference remained significant at 6 months $(p<0.05)$ whereas after 12 months of aging, there wasn't any difference any more ( $p>0.05)$ (Table 5).

\section{Discussion}

The quality of the root canal filling is essential in the evaluation of the sealing; after bonding the post in the root canal, only the last $4 \mathrm{~mm}$ apical of the canal filling is able to ensure apical sealing of the canal, the rest to be ensured by our reconstitution [11]. We have chosen the most commonly used and most universally accepted lateral condensation method, as well as the molded single cone technique adapted to the morphology of the canal [12]. A study on the fluid filtration during different endodontic filling techniques shows better results with these techniques than with vertical condensation [13].

The canal obturation was performed with gutta percha associated with a resin-based root canal cement which has a better sealing efficacy and a greater thermal stability and resorption than the cements based on zinc oxide eugenol [1]. The cement used in our study is the AH Plus Jet; it has already been tested for permeability by the fluid filtration method in the endodontically sealed teeth and the authors conclude that it is more resistant to leakage compared to other endodontic cements tested [14].

In the adhesion protocol of the bonding composite resin to the root dentinal substrate, a chemical co-initiator was used to improve the rate of polymerization of the composite resin in the channel [2]. One of the difficulties of bonding the resin within the channel is the transmission of the activating light of the polymerization into the deepest parts of the channel. When the transmission of the light source is poor, it results in an insufficient degree of conversion of the monomers of the composite adhesive resin [15]. In our study, we used posts known for their high degree of translucency and clear, translucent colors of the composite resin for bonding. Goracci, et al. [2] have moreover demonstrated that the translucency of the luting agent is a more significant factor than the translucency of the post in the efficiency of intraradicular bonding [15].
The first observation on the results of our experiment comes from the difference noticed between the average of the initial values of the permeability of the endodontic obturations of the root and the values obtained after bonding of the post. This is explained by the fact that gutta percha does not have a chemical adhesion, unlike the adhesive system [10].

In groups A and B in which the adhesive used is Prime and Bond Active, there is no statistically significant difference between the selfetch and etch-and-rinse strategies. These results are in agreement with those of Bitter [16]. Bakaus [17] give an advantage to the self-etch strategy in intra-radicular bonding efficiency, their approach is based on push-out bond strength testing and SEM observation. The equal performance of the two universal adhesive application strategies has already been demonstrated in the coronary dentin [18]. The present investigation highlights the important presence of isopropanol in the universal adhesive tested. The role of this solvent is to keep the monomers and the other contents in solution and helps infiltrate and form hydrophobic, water insoluble complex in the hybrid layer [19]. The solvent content seems to be primordial in attaining the adhesive goals.

When analyzing the variation of the sealing values during aging, the universal adhesive shows no significant differences at 6 and 12 months from its initial values whether it is used in self-etch or etchand-rinse mode [20].

Likewise, Prime and Bond XP, an adhesive pre-etch system chosen as a control, does not show significant differences at 6 and 12 months compared to its initial values.

We validate our initial hypothesis because the universal adhesive gives the same results regardless of its strategy of use and these results remain stable at 12 months.

\section{Acknowledgments}

The authors thank the manufacturer for the kind support of the materials used in the study. The authors thank Dr H. Ferroudji for experimental help. 


\section{Declaration of interest}

The authors report no conflict of interest. The authors alone are responsible for the content and writing of the paper.

\section{References}

1. Angerame D, De Biasi M, Cattaruzza M, Franco V, Turco G, et al. (2016) Resistance of endodontically treated roots restored with different fibre post systems with or without post space preparation: in vitro analysis and SEM investigation. GiornaleItaliano di Endodonzia 30: 111-119.

2. Goracci C, Ferrari M (2011) Current perspectives on post systems: a literature review. Aust Dent J 56: 77-83. [Crossref]

3. Veríssimo C, SimamotoJúnior PC, Soares CJ, Noritomi PY, Santos-Filho PC (2014) Effect of the crown, post, and remaining coronal dentin on the biomechanical behavior of endodontically treated maxillary central incisors. J Prosthet Dent 111: 234-246. [Crossref]

4. Sterzenbach G, Karajouli G, Naumann M, Peroz I, Bitter K (2012) Fiber post placement with core build-up materials or resin cements-an evaluation of different adhesive approaches. Acta Odontol Scand 70: 368-376. [Crossref]

5. Esclassan Noirrit E, Grégoire G, Cournot M (2008) Morphological study of fiberreinforced post-bonding system-root dentin interface by evaluation of two bonding systems. Journal of Dentistry 36: 204-213. [Crossref]

6. Bachicha WS, DiFiore PM, Miller DA, Lautenschlager EP, Pashley DH (1998) Microleakage of endodontically treated teeth restored with posts. J Endod 24: 703-708. [Crossref]

7. Grégoire G, Guignes P, Millas A (2005) Effect of self-etching adhesives ondentin permeability in a fluid flow model. J Prosthet Dent 93: 56-63. [Crossref]

8. Bouillaguet S, Shaw L, Barthelemy J, Krejci I, Wataha JC (2008) Long-term sealing ability of Pulp Canal Sealer, AH-Plus, GuttaFlow and Epiphany. Int Endod J 41: 219226. [Crossref]

9. Peng L, Ye L, Tan H, Zhou X (2007) Outcome of root canal obturation by warm guttapercha versus cold lateral condensation: a meta-analysis. Journal of Endodontics 33: 106-109. [Crossref]
10. Özkurt-Kayahan Z, Barut G, Ulusoy Z, Oruçoğlu H, Kayahan MB, et al. (2017) Influence of Post Space Preparation on the Apical Leakage of Calamus, SingleCone and Cold Lateral Condensation Obturation Techniques: A Computerized Fluid Filtration Study. J Prosthodont 28: 587-591. [Crossref]

11. Wu MK, Pehlivan Y, Kontakiotis EG, Wesselink PR (1998) Microleakage along apical root fillings and cemented posts. J Prosthet Dent 79: 264-269. [Crossref]

12. Whitworth J (2005) Methods of filling root canals: principles and practices. Endodontic Topics 12: 2-24.

13. Wu MK, van der Sluis LW, Ardila CN, Wesselink PR (2003) Fluid movement along the coronal two-thirds of root fillings placed by three different gutta-percha techniques. Int Endod J 36: 533-540. [Crossref]

14. Akhavan H, Zahdabadi F, Mehrvarzfar P, Ahmadi Birjandi A (2011) Comparative study on the microleakage of three root canal sealers. Iran Endod J 6: 1-5. [Crossref]

15. Juloski J, Goracci C, Tsintsadze N, Carrabba M, Vichi A, et al. (2015) Influence of luting agent translucency on fiber post retention. Eur J Oral Sci 123: 116-121. [Crossref]

16. Bitter K, Gläser C, Neumann K, Blunck U, Frankenberger R (2014) Analysis of ResinDentin Interface Morphology and Bond Strength Evaluation of Core Materials for One Stage Post-Endodontic Restorations. PLoS ONE 9: e86294. [Crossref]

17. Bakaus TE, Gruber YL, Reis A, Gomes JC, Gomes GM (2019) Bonding properties of universal adhesives to root canals prepared with different rotary instruments. J Prosthet Dent 121: 298-305. [Crossref]

18. Hanabusa M, Mine A, Kuboki T, Momoi Y, Van Ende A, et al. (2012) Bonding effectiveness of a new 'multi-mode' adhesive to enamel and dentine. $J$ Dent 40: 475484. [Crossref]

19. Grégoire G, Sharrock P, Prigent Y (2016) Performance of a universal adhesive on etched and non-etched surfaces: Do the results match the expectations?. Mater Sci Eng C Mater Biol Appl 66: 199-205. [Crossref]

20. Delannée M, Grégoire G, Vergnes JN, Sharrock P (2013) Fluid flow through dentineself-etch resin interface during long term in vitro aging. Mater Sci Eng C Mater Biol Appl 33: 3711-3715. [Crossref]

Copyright: (C2019 Grégoire G. This is an open-access article distributed under the terms of the Creative Commons Attribution License, which permits unrestricted use, distribution, and reproduction in any medium, provided the original author and source are credited. 